\title{
A note on Dasgupta, Hammond, and Maskin's (1979) domain richness condition
}

Citation for published version (APA):

Bochet, O. L. A., \& Klaus, B. E. (2007). A note on Dasgupta, Hammond, and Maskin's (1979) domain richness condition. METEOR, Maastricht University School of Business and Economics. METEOR Research Memorandum No. 039 https://doi.org/10.26481/umamet.2007039

Document status and date:

Published: 01/01/2007

DOI:

10.26481/umamet.2007039

Document Version:

Publisher's PDF, also known as Version of record

\section{Please check the document version of this publication:}

- A submitted manuscript is the version of the article upon submission and before peer-review. There can be important differences between the submitted version and the official published version of record.

People interested in the research are advised to contact the author for the final version of the publication, or visit the DOI to the publisher's website.

- The final author version and the galley proof are versions of the publication after peer review.

- The final published version features the final layout of the paper including the volume, issue and page numbers.

Link to publication

\footnotetext{
General rights rights.

- You may freely distribute the URL identifying the publication in the public portal. please follow below link for the End User Agreement:

www.umlib.nl/taverne-license

Take down policy

If you believe that this document breaches copyright please contact us at:

repository@maastrichtuniversity.nl

providing details and we will investigate your claim.
}

Copyright and moral rights for the publications made accessible in the public portal are retained by the authors and/or other copyright owners and it is a condition of accessing publications that users recognise and abide by the legal requirements associated with these

- Users may download and print one copy of any publication from the public portal for the purpose of private study or research.

- You may not further distribute the material or use it for any profit-making activity or commercial gain

If the publication is distributed under the terms of Article $25 \mathrm{fa}$ of the Dutch Copyright Act, indicated by the "Taverne" license above, 
Olivier Bochet, Bettina Klaus

A Note on Dasgupta, Hammond, and Maskin's (1979) Domain Richness Condition

$\mathrm{RM} / 07 / 039$

JEL code: D71

\section{METEबrR}

Maastricht research school of Economics

of TEchnology and ORganizations

Universiteit Maastricht

Faculty of Economics and Business Administration

P.O. Box 616

NL - 6200 MD Maastricht

phone : ++31433883830

fax : ++31433884873 


\title{
A Note on Dasgupta, Hammond, and Maskin's (1979) Domain Richness Condition*
}

\author{
Olivier Bochet ${ }^{\dagger} \quad$ Bettina Klaus ${ }^{\ddagger}$
}

October 2007

\section{Summary}

We discuss a problem concerning Dasgupta, Hammond, and Maskin's (1979) definition of a rich domain and a very well-known result they established for these domains: on rich domains, if a social choice function is implementable in Nash strategies, then it is truthfully implementable in dominant strategies (Dasgupta et al., 1979, Theorem 7.2.3). This result is cited many times in later papers, e.g., Laffont and Maskin (1982, Theorem 4) and Maskin (1985, Theorem 7). Dasgupta, Hammond, and Maskin's (1979) proof of this result essentially is based on showing that (Maskin) monotonicity implies strategy-proofness (or equivalently independent person-by-person monotonicity IPM).

In the sequel we abbreviate Dasgupta, Hammond, and Maskin (1979) by DHM. We describe DHM's model in Section 2.

In Section 3 we first construct an example of a DHM rich domain and a social choice function that is monotonic but not strategy-proof (Example 1). ${ }^{1}$ This suggests that DHM's rich domain definition is not sufficient to show that monotonicity implies strategy-proofness (or that Nash implementability implies truthful implementability in dominant strategies). We then investigate which step in DHM's proof is problematic - since DHM do not give a direct proof of the result, we reproduce Maskin's (1985) proof. $^{2}$

In Section 4, we consider the presentation of DHM's definition of a rich domain in Maskin and Sjöström (2002). It turns out that their definition of a rich domain is different from DHM's original definition. With this adjusted richness condition the proof that monotonicity implies strategy-proofness is correct.

\footnotetext{
${ }^{*}$ B. Klaus thanks the Netherlands Organisation for Scientific Research (NWO) for its support under grant VIDI-452-06-013.

${ }^{\dagger}$ Department of Economics, Maastricht University, P.O. Box 616, 6200 MD Maastricht, The Netherlands; e-mail: o.bochet@algec.unimaas.nl

${ }^{\ddagger}$ Corresponding Author: Department of Economics, Maastricht University, P.O. Box 616, 6200 MD Maastricht, The Netherlands; e-mail: b.klaus@algec.unimaas.nl

${ }^{1}$ The social choice function described in Example 1 is implementable in Nash strategies, but it is not truthfully implementable in dominant strategies.

${ }^{2}$ We discuss the problem in the original proof in Footnote 6.
} 


\section{The Model}

We describe the essential elements of the model as introduced in DHM and Maskin (1985) for more details we refer to these articles.

Let $A$ be a set of (feasible) social alternatives and $I=\{1, \ldots, n\}$ be a finite set of agents (in Maskin and Sjöström, 2002, $N$ denotes the set of agents). Each agent $i \in I$ has a preference ordering or preference relation $R_{i}$ on the set $A$. Alternatively (as in Maskin, 1985), we can represent agent $i$ 's preference relation by a utility function $u_{i}: A \rightarrow \mathbb{R}$. By $\mathcal{R}_{A}$ we denote the class of all preference relations on $A$ and $\mathbf{R}$ denotes the set of preference profiles $R=\left(R_{i}\right)_{i \in I}$ such that for all $i \in I, R_{i} \subseteq \mathcal{R}_{A}$. A social choice function $f: \mathbf{R} \rightarrow A$ is a function that assigns to every preference profile $R \in \mathbf{R}$ a social alternative $f(R) \in A .^{3}$

First, we discuss the incentive property strategy-proofness, which requires that no agent ever benefits from misrepresenting his preference relation. For agent $i \in I$, preference profile $R \in \mathbf{R}$, and preference relation $R_{i}^{\prime} \in \mathcal{R}_{A}$, we obtain preference profile $\left(R_{i}^{\prime}, R_{-i}\right) \in \mathbf{R}$ by replacing $R_{i}$ at $R$ by $R_{i}^{\prime}$.

Strategy-Proofness: A social choice function $f$ is strategy-proof if $\forall R \in \mathbf{R}, \forall i \in I$, and $\forall \bar{R}_{i} \in \mathcal{R}_{A}, f(R) R_{i} f\left(\bar{R}_{i}, R_{-i}\right)$.

In game theoretical terms, a solution is strategy-proof if in its associated direct revelation game form, it is a weakly dominant strategy for each agent to announce his true preference relation.

Next, we define monotonicity. Loosely speaking, a social choice function is monotonic if an alternative $a$ that is chosen at preference profile $R$ is also chosen at a preference profile $R^{\prime}$ at which $a$ is considered (weakly) better by all agents.

Monotonicity (DHM): "A social choice function $f$ is monotonic if $\forall\left\{R, R^{\prime}\right\} \subseteq \mathbf{R}, \forall a \in A$, if $f(R)=a$ and if $\forall i \in I, \forall b \in A, a R_{i} b \Rightarrow a R_{i}^{\prime} b$, then $f\left(R^{\prime}\right)=a . "$

If $\left\{R, R^{\prime}\right\} \subseteq \mathbf{R}$ and $a \in A$ such that $\forall i \in I, \forall b \in A, a R_{i} b \Rightarrow a R_{i}^{\prime} b$, then we call $R^{\prime}$ a monotonic transformation of $R$ at $a$.

\section{A Problem with DHM's original Richness Condition}

We now quote DHM's definition of a rich domain.

Rich Domain (DHM): "For a set of alternatives, $A$, the domain $\mathcal{R} \subseteq \mathcal{R}_{A}$ is said to be rich iff $\forall\left\{R, R^{\prime}\right\} \subseteq \mathcal{R}$ and $\forall\{a, b\} \subseteq A$ such that $a R b \Rightarrow a R^{\prime} b$ and $a P b \Rightarrow a P^{\prime} b$, then, there exists $R^{\prime \prime} \in \mathcal{R}$ such that $\forall c \in A, a R c \Rightarrow a R^{\prime \prime} c$ and $b R^{\prime} c \Rightarrow b R^{\prime \prime} c$. If $\mathcal{R}_{i}$ is rich for all $i \in I$, then $\mathbf{R}=\Pi \mathcal{R}_{i}$ will also be called rich."

Maskin (1985) calls a rich domain monotonically closed. For completeness, we also quote Maskin's definition of a monotonically closed domain.

\footnotetext{
${ }^{3}$ DHM and Maskin (1985) consider social choice rules/correspondences $f: \mathbf{R} \rightrightarrows A$, but the results we refer to only concern single-valued social choice rules/correspondences. In all definition and results we quote, we will adjust notation in order to accommodate for single-valuedness.
} 
Monotonically Closed Domain (Maskin, 1985): "A class $U$ of utility functions is a monotonically closed domain if, for all pairs $\left\{u, u^{\prime}\right\} \subseteq U$ and $\{a, b\} \subseteq A$ such that (i) $u(a) \geq u(b)$ implies $u^{\prime}(a) \geq u^{\prime}(b)$ and (ii) $u(a)>u(b)$ implies $u^{\prime}(a)>u^{\prime}(b)$, there exists $u^{\prime \prime} \in U$ such that for all $c \in A$ (iii) $u(a) \geq c$ implies $u^{\prime \prime}(a) \geq u^{\prime \prime}(c)$, and (iv) $u^{\prime}(b) \geq u^{\prime}(c)$ implies $u^{\prime \prime}(b) \geq u^{\prime \prime}(c)$."

We are interested in the relationship between monotonicity and strategy-proofness. A well-known result that is implied by DHM's results and that is quoted in the literature is that on rich domains, monotonicity implies strategy-proofness. DHM's Theorem 7.2.3 and Maskin's Theorem 7 are phrased slightly differently, but both results immediately induce the above relationship of monotonicity and strategy-proofness on rich domains. ${ }^{4}$

The following example demonstrates that DHM's richness condition is not sufficient to show that monotonicity implies strategy-proofness.

Example 1. Let $I=\{1\}, A=\{a, b, c, d\}$, and $\mathcal{R}=\left\{R, R^{\prime}\right\}$ where $R$ and $R^{\prime}$ are strict orderings on $A$ such that $a P b P c P d$ and $d P^{\prime} c P^{\prime} b P^{\prime} a$. The social choice function $f$ is defined by $f(R)=c$ and $f\left(R^{\prime}\right)=b$.

Since there is a preference reversal between any two alternatives when moving from $R$ to $R^{\prime}$ or vice versa, there is no pair of alternatives $\{a, b\} \subseteq A, a \neq b$, such that $\left[a R b \Rightarrow a R^{\prime} b\right.$ and $\left.a P b \Rightarrow a P^{\prime} b\right]$ or $\left[a R^{\prime} b \Rightarrow a R b\right.$ and $\left.a P^{\prime} b \Rightarrow a P b\right]$. Thus, the domain $\mathcal{R}$ is rich according to DHM. Furthermore, none of the preference relations is a monotonic transformation of the other preference relation. Hence, $f$ satisfies monotonicity. However, $f$ is not strategy-proof. For instance, if agent 1 has preference relation $R$, then reporting $R^{\prime}$ instead would be beneficial because $b=f\left(R^{\prime}\right) P f(R)=c$.

Example 1 already indicates a crucial situation that does not seem to be addressed in DHM's proof, namely the situation that there exist $R, R^{\prime} \in \mathbf{R}$ and $i \in I$ such that $R^{\prime}=$ $\left(R_{i}^{\prime}, R_{-i}\right), f(R)=a, f\left(R^{\prime}\right)=b, b P_{i} a$, and $a P_{i}^{\prime} b .^{5}$

We now go through Maskin's (1985) proof. Maskin (1985) uses the following condition that is equivalent to strategy-proofness when modified for social choice functions.

Independent Person-by-Person Monotonicity (IPM): " $\mathrm{A}$ social choice function $f$ satisfies IPM if for all $\left(u_{1}, \ldots, u_{n}\right) \in U_{1} \times U_{2} \times \ldots \times U_{n}$, all $i$, all $\bar{u}_{i} \in U_{i}$ and all $a, b \in A$ such that $f\left(u_{1}, \ldots, u_{n}\right)=a$ and $\bar{u}_{i}(a)>\bar{u}_{i}(b)$, it must be the case that $f\left(\bar{u}_{i}, u_{-i}\right) \neq b . "$

Lemma 1. A social choice function $f$ satisfies IPM if and only if it is strategy-proof.

Proof. Assume that $f$ does not satisfy IPM. Then, there exist $\left(u_{1}, \ldots, u_{n}\right) \in U_{1} \times U_{2} \times \ldots \times U_{n}$, $i \in I$, and $\bar{u}_{i} \in U_{i}$ such that $f\left(u_{1}, \ldots, u_{n}\right)=a, f\left(\bar{u}_{i}, u_{-i}\right)=b$, and $\bar{u}_{i}(a)>\bar{u}_{i}(b)$. Hence, $f$ does not satisfy strategy-proofness (agent $i$ with utility function $\bar{u}_{i}$ benefits by reporting $u_{i}$ ).

\footnotetext{
${ }^{4}$ DHM's Theorem 7.2.3: If $\mathbf{R}$ is a rich domain, then if the social choice function $f: \mathbf{R} \rightarrow A$ is implementable in Nash strategies, it is truthfully implementable in dominant strategies.

${ }^{5}$ It is clear from Example 1 that the problem extends to environments with more than one agent.

${ }^{6}$ Note that Maskin's (1985) definition of IPM quoted here is different from DHM's definition of IPM. DHM's Independent Person-by-Person Monotonicity (IPM): "The social choice function $f: \mathbf{R} \rightarrow A$ satisfies IPM iff $\forall R \in \mathbf{R}, \forall i \in I, \forall R_{i}^{\prime} \in \mathcal{R}_{i}, \forall\{a, b\} \subseteq A$, if $f(R)=a$ and $a R_{i} b \Rightarrow a P_{i}^{\prime} b$, then $f\left(R_{i}^{\prime}, R_{-i}\right) \neq b$."

With DHM's definition of IPM the equivalence between IPM and strategy-proofness is wrong. Thus, DHM's Theorem 4.3.1 is not correct. The problem with the proof of DHM's Theorem 4.3.1 is similar to the problem that we will discuss for the proof of Maskin's (1985) Theorem 7. (DHM, page 198, line 2, write that "Since $b P_{i} a$, we conclude by IPM, ..." The problem is that IPM according to DHM can only be applied in this situation if also $b R_{i}^{\prime} a$, which is not necessarily the case.)
} 
Assume that $f$ does not satisfy strategy-proofness. Then, there exist $\left(u_{1}, \ldots, u_{n}\right) \in U_{1} \times$ $U_{2} \times \ldots \times U_{n}, i \in I$, and $\bar{u}_{i} \in U_{i}$ such that $f\left(u_{1}, \ldots, u_{n}\right)=a, f\left(\bar{u}_{i}, u_{-i}\right)=b$, and $u_{i}(b)>$ $u_{i}(a)$. Hence, $f$ does not satisfy IPM (by IPM, $f\left(\bar{u}_{i}, u_{-i}\right)=b$ and $u_{i}(b)>u_{i}(a)$ imply $\left.f\left(u_{1}, \ldots, u_{n}\right) \neq a\right)$.

We now quote (Maskin, 1985, Theorem 7) and its proof.

Theorem 7 (Maskin, 1985): "If $U_{i}$ is monotonically closed for all $i$, then if the social choice function $f$ is implementable in Nash equilibrium, it is truthfully implementable in dominant strategies."

Proof. "If $f$ is implementable in Nash equilibrium, then it is monotonic. If $f$ violates IPM, there would exist $\left(u_{1}, \ldots, u_{n}\right), \bar{u}_{i}, a$, and $b$ such that $f\left(u_{1}, \ldots, u_{n}\right)=a$ and $\overline{\mathbf{u}}_{\mathbf{i}}(\mathbf{a})>\overline{\mathbf{u}}_{\mathbf{i}}(\mathbf{b})$ but $f\left(\bar{u}_{i}, u_{-i}\right)=b$. From the monotonic closure of $U_{i}$, however, there exists $\overline{\bar{u}}_{i} \in U_{i}$ such that for all $c$

$$
u_{i}(a) \geq u_{i}(c) \text { implies } \overline{\bar{u}}_{i}(a) \geq \overline{\bar{u}}_{i}(c)
$$

and

$$
\bar{u}_{i}(b) \geq \bar{u}_{i}(c) \text { implies } \overline{\bar{u}}_{i}(b) \geq \overline{\bar{u}}_{i}(c) .
$$

From monotonicity applied to $\left(u_{i}, u_{-i}\right)$ and $\left(\overline{\bar{u}}_{i}, u_{-i}\right)$, we have $f\left(\overline{\bar{u}}_{i}, u_{-i}\right)=a$. But from monotonicity applied to $\left(\bar{u}_{i}, u_{-i}\right)$ and $\left(\overline{\bar{u}}_{i}, u_{-i}\right), f\left(\overline{\bar{u}}_{i}, \bar{u}_{-i}\right)=b$, a contradiction of $f$ 's singlevaluedness. Therefore, $f$ satisfies IPM, and so is truthfully implementable in dominant strategies."

It is obvious that the above theorem and proof should also establish the result that on rich domains, monotonicity implies strategy-proofness. So what goes wrong?

Let's look at lines 2 and 3 of the proof, particularly the parts that are marked in boldface. From the assumption that IPM is violated one does not obtain pairs $\left\{u_{i}, u_{i}^{\prime}\right\} \subseteq U_{i}$ and $\{a, b\} \subseteq A$ such that (i) and (ii) in the definition of a monotonically closed domain are satisfied. To apply the monotonic closure condition, i.e., to satisfy (i) and (ii), one would need in addition to $\bar{u}_{i}(a)>\bar{u}_{i}(b)$ that $u_{i}(a) \geq u_{i}(b)$. However, if $\bar{u}_{i}(a)>\bar{u}_{i}(b)$ and $u_{i}(a)<u_{i}(b)$ (a case that we cannot exclude as demonstrated in Example 1), then the fact that the domain is monotonically closed is not enough to complete the proof.

\section{Maskin and Sjöström's (2002) Richness Condition}

Let us now consider Maskin and Sjöström's (2002) definition of a rich domain. For the additional notation we use we refer to Maskin and Sjöström (2002). ${ }^{7}$ Although the authors state that they replicate some of DHM's results, we show below that this is not the case. Before doing so, we first introduce the notion of improvement used in Maskin and Sjöström's (2002) definition of a rich domain. With this definition, the problems we encountered in DHM are fixed.

Improvement: "If $u_{i}(a, \theta) \geq u_{i}(b, \theta)$ and $u_{i}\left(a, \theta^{\prime}\right) \leq u_{i}\left(b, \theta^{\prime}\right)$ and at least one inequality is strict, then $b$ improves with respect to a for agent $i$ as the state changes from $\theta$ to $\theta^{\prime} . "$

\footnotetext{
${ }^{7}$ Essentially, by equating characteristics with preferences we can translate Maskin and Sjöström's notation to the notation used so far. For example, $u_{i}(a, \theta)$ would correspond to $u_{i}(a)$ and $u_{i}\left(a, \theta^{\prime}\right)$ would correspond to $u_{i}^{\prime}(a)$.
} 
Agent $i$ 's lower contour set at $(a, \theta) \in A \times \Theta$ is $L_{i}(a, \theta):=\left\{b \in A: u_{i}(a, \theta) \geq u_{i}(b, \theta)\right\}$.

Rich domain (Maskin and Sjöström, 2002): "For any $a, b \in A$ and any $\theta, \theta^{\prime} \in \Theta$, if, for all $i \in N, b$ does not improve with respect to $a$ for when the state changes from $\theta$ to $\theta^{\prime}$, then there exists $\theta^{\prime \prime} \in \Theta$ such that $L_{i}(a, \theta) \subseteq L_{i}\left(a, \theta^{\prime \prime}\right)$ and $L_{i}\left(b, \theta^{\prime}\right) \subseteq L_{i}\left(b, \theta^{\prime \prime}\right)$ for all $i \in N$."

Given a social choice function $f$, we define $\bar{f}: \mathcal{R}(\Theta) \rightarrow A$ such that $\bar{f}(R(\theta))=f(\theta)$ for all $\theta \in \Theta$. If $f$ is monotonic, then $\bar{f}$ is well defined.

Coalitional Strategy-Proofness (Maskin and Sjöström, 2002): "A social choice function $f$ is coalitionally strategy-proof if for all $\theta \in \Theta$, for all nonempty coalitions $C \subseteq N$, and all preferences $R_{C}^{\prime} \in \mathcal{R}(\Theta)$, there exists $i \in C$ such that $u_{i}\left(\bar{f}\left(R_{C}, R_{-C}\right), \theta\right) \geq u_{i}\left(\bar{f}\left(R_{C}^{\prime}, R_{-C}\right), \theta\right)$, where $\left(R_{C}, R_{-C}\right)=\left(R_{C}(\theta), R_{-C}(\theta)\right)$."

Note that coalitional strategy-proofness implies ordinary strategy-proofness.

Theorem 7 (Maskin and Sjöström, 2002): "Suppose $f$ is a monotonic social choice function, the domain is rich, and the preference domain has a product structure $\mathcal{R}(\Theta)=$ $\times_{i=1}^{n} \mathcal{R}_{i}$. Then $f$ is coalitionally strategy-proof."

Proof. "Let $f$ be as hypothesized. Let $C \subseteq N$ be any coalition. Suppose that the true preference profile in state $\theta$ is $R=\left(R_{C}, R_{-C}\right)=R(\theta)$. Consider a preference profile $R^{\prime}=$ $R\left(\theta^{\prime}\right)=\left(R_{C}^{\prime}, R_{-C}\right)$ with $R_{i}^{\prime} \neq R_{i}$ for $i \in C$ and $R_{i}^{\prime}=R_{i}$ for $i \notin C$. Let $a=f(\theta)=\bar{f}\left(R_{C}, R_{-C}\right)$ and $b=f\left(\theta^{\prime}\right)=\bar{f}\left(R_{C}^{\prime}, R_{-C}\right)$. If $a=b$ then $u_{i}\left(\bar{f}\left(R_{C}, R_{-C}\right), \theta\right) \geq u_{i}\left(\bar{f}\left(R_{C}^{\prime}, R_{-C}\right), \theta\right)$ holds trivially for all $i \in C$, so suppose $a \neq b$.

We claim that there exists $i \in C$ such that $b$ improves with respect to $a$ for agent $i$ as the state changes from $\theta$ to $\theta^{\prime}$. Notice that because $R_{i}^{\prime}=R_{i}$ for $i \notin C, b$ cannot improve with respect to $a$ for any such agent. Hence, if the claim is false, the definition of rich domain implies that there exists $\theta^{\prime \prime} \in \Theta$ such that $L_{i}(a, \theta) \subseteq L_{i}\left(a, \theta^{\prime}\right)$ and $L_{i}\left(b, \theta^{\prime}\right) \subseteq L_{i}\left(b, \theta^{\prime \prime}\right)$ for all $i \in N$. But then, from monotonicity, we have $a=f\left(\theta^{\prime \prime}\right)$ and $b=f\left(\theta^{\prime \prime}\right)$, a contradiction of $f^{\prime}$ 's single-valuedness. Hence the claim holds after all.

But $b$ improving with respect to $a$ for agent $i \in C$ implies that

$$
u_{i}\left(\bar{f}\left(R_{C}, R_{-C}\right), \theta\right) \geq u_{i}\left(\bar{f}\left(R_{C}^{\prime}, R_{-C}\right), \theta\right),
$$

and so $f$ is coalitionally strategy-proof as claimed."

To see that the proof indeed works, for some $i \in I$ consider the case $u_{i}(a, \theta)<u_{i}(b, \theta)$ and $u_{i}\left(a, \theta^{\prime}\right)>u_{i}\left(b, \theta^{\prime}\right)$ (cf. Example 1). Thus, by the definition of an improvement, $b$ does not improve with respect to $a$ for agent $i$ as the state changes from $\theta$ to $\theta^{\prime}$. Hence, by Maskin and Sjöström's (2002) definition of a rich domain, there exists $\theta^{\prime \prime}$ such that $L_{i}(a, \theta) \subseteq L_{i}\left(a, \theta^{\prime \prime}\right)$ and $L_{i}\left(b, \theta^{\prime}\right) \subseteq L_{i}\left(b, \theta^{\prime \prime}\right)$. Hence, the domain identified in Example 1 is not rich according to Maskin and Sjöström (2002), but it is rich according to DHM's original richness definition.

Remark 1. The main role the richness condition has is to guarantee that for certain preference profiles $R, R^{\prime} \in \mathbf{R}$ and certain alternatives $a, b \in A$ a third preference profile $R^{\prime \prime} \in \mathbf{R}$ exists such that (1) $R^{\prime \prime}$ is a monotonic transformation of $R$ at $a$ and $(2) R^{\prime \prime}$ is a monotonic transformation of $R^{\prime}$ at $b$, or alternatively, (3) $R^{\prime \prime}$ is a monotonic transformation of $R^{\prime}$ at $a$ and (2) $R^{\prime \prime}$ is a monotonic transformation of $R$ at $b$. 
The table below demonstrates that the two richness definitions in DHM and Maskin and Sjöström (2002) induce the existence of different monotonic transformations. The entry "DHM" indicates that according to DHM a certain monotonic transformation $R^{\prime \prime}$ exists and the entry "MS" indicates that according to Maskin and Sjöström (2002) a certain monotonic transformation $R^{\prime \prime}$ exists.

\begin{tabular}{|c|c|c|c|c|c|c|}
\hline & $\exists R^{\prime \prime}$ s.t. & (1) \& (2) & $\exists R^{\prime \prime}$ s.t. & $(3) \&(4)$ \\
\hline$a P_{i}$ & & $a P_{i}^{\prime} b$ & DHM & MS & & MS \\
\hline$a P_{i}$ & $\&$ & $a I_{i}^{\prime} b$ & & & DHM & MS \\
\hline$a P_{i}$ & $\&$ & $b P_{i}^{\prime} a$ & & & & MS \\
\hline$a I_{i} b$ & $\&$ & $a P_{i}^{\prime} b$ & DHM & MS & & \\
\hline$a I_{i} b$ & $\&$ & $a I_{i}^{\prime} b$ & DHM & MS & DHM & MS \\
\hline$a I_{i} b$ & $\&$ & $b P_{i}^{\prime} a$ & DHM & & & MS \\
\hline$b P_{i} c$ & $\&$ & $a P_{i}^{\prime} b$ & & MS & & \\
\hline$b P_{i}$ & $\&$ & $a I_{i}^{\prime} b$ & & MS & DHM & \\
\hline$b P_{i} c$ & $\&$ & $b P_{i}^{\prime} a$ & DHM & MS & DHM & MS \\
\hline
\end{tabular}

We see from the table above that according to the richness definition used, different monotonic transformations are required to exist. Maskin and Sjöström's (2002) richness also "covers" the critical case $a P_{i} b$ and $b P_{i}^{\prime} a$ indicated in Example 1.

\section{References}

Dasgupta, P., Hammond, P., and Maskin, E. (1979): "The Implementation of Social Choice Rules: some general Results on Incentive Compatibility." Review of Economic Studies, 46: $181-216$.

Laffont, J.-J. and Maskin, E. (1982): "Nash and Dominant Strategy Implementation in Economic Environments." Journal of Mathematical Economics, 10: 17-47.

Maskin, E. (1985): "Theory of Implementation in Nash Equilibrium." In L. Hurwicz, D. Schmeidler, and H. Sonnenschein, editors, Social Goals and Social Organization. Cambridge University Press, Cambridge.

Maskin, E. S. and Sjöström, T. (2002): "Implementation Theory." In K. J. Arrow, A. K. Sen, and K. Suzumura, editors, Handbook of Social Choice and Welfare. Elsevier, North Holland. 